UDC 327.8

Submitted: 14.01 .2016

LBC $86.38(533)(5 И р н)$

Accepted: 30.08 .2016

\title{
THE SHIA FACTOR IN RELATIONS BETWEEN THE ARAB COUNTRIES OF THE PERSIAN GULF AND IRAN
}

\author{
Vladimir P. Kirichenko \\ Institute of Oriental Studies, Russian Academy of Sciences, Moscow, Russian Federation
}

\begin{abstract}
The author studies the influence of the "Shia factor" on the relations between Iran and the Gulf Arab countries. In most countries of the Persian Gulf, there are Shia communities that constitute a significant part of the population. After the Islamic revolution of 1979 relations between Iran and most Arab countries have become particularly tense. In the 1980s, the Gulf monarchies also became wary of exporting the Islamic revolution in their countries. This was due to the fact that, being inspired by the success of the co-religionists in Iran, the Arab Shiites became more involved in politics. It should be noted that the way the Arab Gulf countries treat the Shiites in the region is influenced by the fact that Iran and the Arab Gulf countries compete for political and economic predominance in the region. Often the Shia Muslims are discriminated by the authorities of the Arab countries, and are regarded as the so-called "fifth column" of Iran. In the author's opinion, the policy of oppression of the Shia Muslims in the Persian Gulf monarchies not only worsens the political situation in these countries, but also complicates relations with neighboring Iran. This policy is not constructive. Moreover, the mythical "Iranian threat" does not go to any comparison with the threat posed by the Islamic State. According to the author, although after the execution of the Shia cleric Sheikh Nimr al-Nimr in Saudi Arabia at the beginning of 2016 Iran's relations with Arab countries became even more strained, the further escalation of the conflict is not in the interests of Iran. Especially now, at the initial stage of removing sanctions against Iran's nuclear program, the military operations against the Shiites in the Arab countries may slow down the process. As for Saudi Arabia, in the event of the outbreak of hostilities Riyadh may seriously damage relations with the United States. This is because Washington sees no benefits in involving Saudi Arabia, its biggest ally in the region, into another armed conflict in the region.
\end{abstract}

Key words: Shia communities, Persian Gulf, Arab countries, Iran, international relations.

УДК 327.8

ББК $86.38(533)(5 И р н)$

Дата поступления статьи: 14.01.2016

Дата принятия статьи: 30.08.2016

\section{ШИИТСКИЙ ФАКТОР В ОТНОШЕНИЯХ АРАБСКИХ СТРАН ПЕРСИДСКОГО ЗАЛИВА И ИРАНА}

\author{
Владимир Павлович Кириченко \\ Институт востоковедения РАН, г. Москва, Российская Федерация
}

\begin{abstract}
Аннотация. Статья посвящена влиянию «шиитского фактора» на отношения Ирана с арабскими странами Персидского залива. В большинстве этих стран существуют шиитские общины. Часто шииты подвергаются дискриминации со стороны властей арабских стран и рассматриваются в качестве «пятой колонны» Ирана. По мнению автора, политика притеснения шиитов в монархиях Персидского залива не только ухудшает политическую обстановку в этих странах, но и усложняет отношения с соседним Ираном. Данная политика не конструктивна, тем более что мифическая «иранская угроза» не идет ни в какое сравнение с той угрозой, которую представляет «Исламское государство».
\end{abstract}

Ключевые слова: шииты, Персидский залив, арабские страны, Иран, международные отношения.

Уже в VII в. обозначилось принципиальное различие в подходе к вопросу о передаче верховной власти в Арабском халифате: из- брание или наследование. На основе этого различия сформировались два направления в исламе: суннизм и шиизм. Шииты (от шиа- 
партия, группа) считали, что право на власть должно передаваться от Мухаммеда по наследству. Так как у пророка не было потомства мужского пола, согласно шиитской доктрине стать имамом имели право только потомки Али ибн Абу Талиба (двоюродного брата и зятя пророка Мухаммеда) и Фатимы (дочери пророка). Сунниты же считали, что имам может быть избран членами мусульманской общины [9, с. 241].

Формируясь в основном на иранской национальной и культурной почве, шиизм постепенно вырос в самостоятельное течение. Несмотря на определенную близость ряда обычаев, со временем в шиизме возобладал национальный иранский подход к исламу. В частности, образ халифа Али (в шиизме - имама Али) воплотил в себе черты иранского народного героя. Постепенно обрастая новыми противоречиями, противостояние между шиитами и суннитами приобрело перманентный характер.

В данной статье мы попытаемся ответить на вопрос: как наличие шиитского населения в государствах Персидского залива отражается на отношениях этих государств с Ираном, являющимся крупнейшей страной, где большинство населения исповедует ислам шиитского толка? Власти ряда арабских государств рассматривают шиитов как агентов влияния Ирана и часто обвиняют эту страну в провоцировании политической нестабильности на Ближнем Востоке. Одновременно в некоторых государствах Персидского залива фактически замалчивается сам факт наличия в них собственных шиитов. Большая или меньшая степень умолчания их присутствия обернулась отсутствием точной статистики на этот счет, поэтому все приводимые ниже данные о численности шиитов в данных странах оценочные и приблизительные.

\section{I}

Коротко охарактеризуем положение шиитов ${ }^{1}$ во всех государствах Персидского залива.

Ирак. В Ираке шииты-имамиты предположительно составляют $60 \%$ населения. Исторически власть в Ираке находилась в руках суннитов, несмотря на тот факт, что в
XIX-XX вв. шииты сделались большинством в населении этой страны [19]. Не исключением был и период правления суннита Саддама Хусейна (1979-2003), когда власть была сосредоточена в руках его приближенных и суннитов из Партии арабского социалистического возрождения (БААС). Заручившись поддержкой шейхов племен и подавив влияние духовных лидеров, иракское руководство добилось раскола в верхушке шиитов. Ситуация изменилась в 2003 г. после вторжения в Ирак США и их союзников и падения баасистского режима. Созданная Хусейном система управления страной была разрушена, и шииты, на которых сделали ставку американцы, впервые получили шанс стать значимой политической силой. Однако отстраненные от власти сунниты были недовольны таким ходом событий, что усугубило кризисную политическую ситуацию.

Обстановка в Ираке обострилась летом 2014 г., когда боевики организации «Исламское государство Ирака и Леванта» (ДАИШ) начали полномасштабное наступление на северные и западные районы страны. В составе ДАИШ воюют сунниты, разделяющие взгляды исламских радикалов, а также добровольцы из числа девиантных и криминальных элементов разного этнического происхождения. Боевики этой организации считают шиитов «неверными», поэтому для шиитского населения агрессивные действия ДАИШ представляют особую опасность.

Бахрейн. В этой стране удельный вес шиитов значительно больше: на их долю приходится 60-65\% всего населения. Тем не менее здесь они тоже подвергаются нападкам и дискриминации со стороны властей [24]. С 1999 г. Бахрейном правит шейх Хамад бен Иса Аль-Халифа (р. 28 января 1950 г.) - представитель суннитской династии, важные государственные посты занимают также сунниты. Как и в Саудовской Аравии, в Бахрейне шииты не могут получить образование и высококвалифицированную работу, им приходится зарабатывать на жизнь в основном физическим трудом. В бахрейнских СМИ освещаются исключительно суннитские религиозные мероприятия, по пятницам по телевидению транслируются проповеди только из суннитских мечетей. 
В марте 2011 г. шииты организовали марш протеста на улицах Манамы, столицы Бахрейна, требуя прекращения притеснений со стороны властей. Для подавления протестов власти страны обратились за помощью к Саудовской Аравии и ОАЭ. Те откликнулись, и в Бахрейн был введен корпус военнослужащих Саудовской Аравии и ОАЭ численностью в 1,5 тыс. человек. С помощью этих внешних сил восстание оппозиции было подавлено. В результате погибло 34 человека, около 1,4 тыс. было арестовано [5, с. 52].

Кувейт. В этой стране шиитов тоже немало - примерно 30 \% населения [18]. Среди них есть потомки уроженцев Восточной провинции Саудовской Аравии и Бахрейна. Часть кувейтских шиитов имеет иранское происхождение и поддерживает деловые/семейные связи со своей родиной. Шиитская община представлена в кувейтском парламенте, занимает важное положение не только в политическом истеблишменте, но и в экономике страны. Особенно заметны шииты среди крупных и средних предпринимателей в сфере торговли [8].

Кувейтские шииты пользуются религиозной свободой, но это свобода относительная. Собрания по случаю амуры (поминальный день, когда происходят специальные церемонии в память Хусейна ${ }^{2}$, внука пророка) им разрешены, а устраивать поминальные шествия не позволяется. В отличие от суннитских мечетей строительство шиитских мечетей не финансируется правительством. Не допускается создание учебных центров для подготовки шиитского духовенства. Шиитам, которые хотели бы стать имамами, приходится получать образование за рубежом, прежде всего в Ираке и Иране, что также не приветствуется. Таким образом, из-за политики властей, хотя и более мягкой, чем в Саудовской Аравии или Бахрейне, но по сути все равно дискриминационной шииты Кувейта чувствуют свою второсортность.

ОАЭ. Положение шиитского меньшинства в ОАЭ, где оно составляет $16 \%$ населения, почти такое же, как в Кувейте. Они пользуются религиозной свободой, но их мечети не получают государственного финансирования [23]. Такжездесь, как и в других странах, входящих в Совет сотрудничества арабс- ких государств Персидского залива (ССАГПЗ), шииты не могут занимать высшие государственные должности, стать госслужащими и работать в силовых ведомствах.

Саудовская Аравия. Шииты составляют от 10 до $15 \%$ всего населения королевства, что при общей его численности в 31 млн человек дает цифру в 3,1-4,6 млн. Из них $80 \%-$ это имамиты [20]. Данное направление шиизма наиболее распространенное в мире. Имамиты признают своими духовными руководителями 12 имамов из рода Али ибн Абу Талиба, двоюродного брата и одного из ближайших соратников пророка Мухаммеда.

Помимо имамитов в стране есть незначительное число шиитов-зейдитов, населяющих провинцию Джизан на саудовско-йеменской границе. Зейдиты выбрали своим имамом Зейда ибн Али, внука третьего шиитского имама Хусейна. В отличие от представителей других шиитских течений, зейдиты не придерживаются принципа такыйа, в соответствии с которым дозволяется, находясь во враждебном окружении, скрывать свою веру [9, с. 246].

Руководство Саудовской Аравии с подозрением относится к шиитам, рассматривая их как нелояльных королевству и даже как потенциальных предателей. В стране осуществляется негласная дискриминация шиитов, выражающаяся в первую очередь в фактическом запрете на их участие в органах государственного управления и на службу в элитных частях вооруженных сил и органах безопасности. У шиитов Саудовской Аравии нет возможности получить религиозное образование [16, p. 170].

Kamap. В эмирате шииты составляют свыше $10 \%$ населения. Они пользуются религиозной свободой. У шиитов есть свои мечети и джафаритские суды, многие шиитские кланы занимают ведущие позиции в строительстве, торговле, сфере услуг и банковском секторе этой богатейшей арабской страны [3].

Оман. Шииты составляют лишь 0,3\% населения страны, однако столь незначительное меньшинство играет видную роль в торговых связях султаната с зарубежными государствами. Оманские шииты не подвергаются репрессиям со стороны правящего режима, который в целом характеризуется терпи- 
мостью по отношению к представителям различных течений внутри ислама [13].

\section{II}

Арабо-израильский конфликт и арабоизраильские войны 1967 и 1973 гг. повсеместно вызвали рост политического самосознания в арабских странах. Определенным раздражителем являлась и великодержавная политика шаха, тревожившая арабских соседей Ирана. С победой Исламской революции 1979 г. отношения Ирана с большинством арабских стран стали еще более напряженными. Стремление оградить Ирак от экспорта исламской революции было одной из причин ирано-иракской войны 1980-1988 гг., в те же годы монархии Персидского залива также опасались проникновения бациллы шиитского «революционаризма» в свои страны. И нельзя отрицать, что, воодушевившись успехами единоверцев в Иране, арабские шииты стали более активно участвовать в политике. В то же время следует отметить, что на отношение к шиитам сказывается соперничество Ирана и арабских стран Персидского залива за политическое и экономическое влияние в регионе.

Из всех стран ССАГПЗ наиболее дружественные отношения с Ираном установились у Омана. Это можно объяснить тем, что в Омане правящая верхушка и большинство населения являются не суннитами, а $и б а д и$ тами (умеренное течение в хариджизме), и поэтому лояльно относятся к шиитам [2]. Власти султаната не опасаются «иранской угрозы», у Омана и Ирана хорошие торговые, экономические связи, общие проекты по освоению месторождений углеводородов [12].

После событий «арабской весны» 2011 г. шииты вновь стали объектом подозрений со стороны суннитских властей. Одновременно усилились и опасения насчет Ирана. Как минимум правящие круги большинства арабских стран Персидского залива были убеждены в том, что после окончания войн в Афганистане и Ираке региональные амбиции Ирана усилились и он активнее, чем прежде, поддерживает арабские шиитские религиозные и идеологические организации, занимающие заметное положение в арабских обще- ствах и действующие легально [1]. Приведем в этой связи только один, но весьма показательный факт: в апреле 2011 г. министры иностранных дел ССАГПЗ обвинили Иран во вмешательстве во внутренние дела Кувейта. Обвинения прозвучали после высылки из страны трех иранских дипломатов, обвиненных в шпионаже. По этому поводу было принято специальное заявление; в нем «министры иностранных дел ССАГПЗ осудили неприкрытое вмешательство Ирана во внутренние дела Кувейта, осуществляемое при помощи создания на его территории шпионских сетей» [11]. ССАГПЗ обещал содействовать спецслужбам Кувейта в принятии мер для обеспечения безопасности.

\section{III}

Насколько обоснованы претензии к Ирану его арабских соседей по Персидскому заливу?

Безусловно, определенные основания для обвинений в адрес Ирана имеются. Государства Персидского залива наверняка помнят и о претензиях шахского Ирана на региональное лидерство, и о попытках властей Исламской Республики Иран поднять иракских шиитов против режима Саддама Хусейна во время ирано-иракской войны, и о поддержке Ираном исламистских шиитских сил во время обострения политического кризиса в Ливане в 2008 году. Однако эти же примеры активизации прошиитской политики говорят и о том, что не Иран - во всяком случае не республиканский Иран - инициировал возникновение ситуаций, побудивших его к такой активизации. Ирано-иракскую войну развязал Саддам Хусейн, а ливанский кризис во многом был обусловлен конфессиональной системой, на которой в этой стране базируется власть. Так, в Ливане резко выросло шиитское население, а пропорции шиитов во власти остались прежними.

В целом политика Ирана, как представляется, носит характер скорее оборонительный и прагматичный, нежели экспансионистский. Иран в первую очередь ориентирован на формирование безопасной среды у своих границ, с одной стороны, и на создание экономических возможностей для достижения своих 
стратегических целей - с другой [14, p. 97]. Даже в годы президента Ахмадинеджада, большого любителя разного рода громких заявлений, в практической политике Ирана, по мнению западных экспертов [15, p. 66], не было выраженных признаков осуществления какого-то плана по свержению арабских режимов в странах Персидского залива силами шиитской оппозиции. Можно исключить и возможность военного вторжения Ирана в эти страны. О нежелании иранского руководства вступать с кем-либо в противоборство говорит и тот факт, что военные расходы Ирана снизились с 25,7 млрд долларов в 2011 г. до 17,7 млрд долларов в 2012 году [17, p. 74]. Как отмечает отечественный исследователь В. Сажин, несмотря на то что Иран стремится стать супердержавой региона, это не означает, что его военно-политические цели носят агрессивный характер [6].

Следует подчеркнуть, что периодически встречающаяся в речах иранских политиков антиарабская риторика в значительной степени обусловлена тем, что арабские монархии Персидского залива являются союзниками «родового» врага Ирана - США. И дело не только в том, что Исламская революция совершалась, помимо прочего, под антиамериканскими лозунгами. Наличие в Бахрейне базы Пятого флота США позволяет Вашингтону контролировать регион Персидского залива. Крупная группировка американских военных остается в Кувейте, базы США находятся в Саудовской Аравии. Американское присутствие в регионе можно объяснить желанием властей этой страны обеспечить контроль над путями транспортировки нефти из стран ССАГПЗ. Тем самым американцы стремятся обеспечить себе доминирующее влияние на мировую энергетическую политику, что противоречит интересам Ирана как одного из крупнейших экспортеров углеводородного сырья в прошлом, после отмены санкций рассчитывающего вернуть утраченные позиции на рынке нефти и газа.

Отношения Ирана с арабскими странами вновь обострились после того, как 2 января 2016 г. МВД Саудовской Аравии объявило о казни 47 человек, обвиненных в террористической деятельности и подстрекательстве к ней. В числе казненных был и шиитский про- поведник Нимр ан-Нимр, арестованный в 2012 г. в ходе акций протеста в населенной шиитами Восточной провинции. Участники акций выступали против дискриминации со стороны саудовских властей [21]. Власти Ирана осудили казнь шиитского проповедника, а недовольные казнью шиитского лидера иранцы осуществили погром саудовского посольства в Тегеране и попытались атаковать консульство в Мешхеде. Следует отметить, что президент Ирана Хасан Роухани осудил эти действия [4]. Акции протеста шиитов по поводу казни ан-Нимра прошли также в Ираке, Бахрейне, Йемене и Ливане. В ответ на нападения на посольство и консульство Эр-Рияд заявил о разрыве дипломатических отношений с Ираном. В официальном заявлении МИД Саудовской Аравии обвинил Тегеран во вмешательстве во внутренние дела королевства. Бахрейн и Судан тоже разорвали дипломатические отношения с Ираном, а ОАЭ понизили их уровень. Роухани заявил 5 января 2016 г., что разрыв дипотношений не поможет Саудовской Аравии скрыть «преступную» казнь ан-Нимра [10].

Столь резкие действия и заявления с обеих сторон позволяют предположить, что в ближайшее время улучшения отношений Ирана и Саудовской Аравии ждать не приходится. В то же время есть основания полагать, что перехода противостояния в вооруженную фазу не будет, так как это невыгодно ни Тегерану, ни Эр-Рияду. Обострение ситуации не в интересах Ирана, особенно сейчас, на начальном этапе снятия санкций по иранской ядерной программе. Военная операция может затормозить этот процесс. Эр-Рияд в случае начала боевых действий может серьезно испортить отношения с США, поскольку Вашингтону невыгодно вовлечение Саудовской Аравии, своего крупнейшего союзника в регионе, в новый вооруженный конфликт.

$$
* * *
$$

Затяжное геополитическое противостояние Ирана со странами Персидского залива, прежде всего с Саудовской Аравией, обострилось. Во-первых, этому способствовало то, что интерес, проявляемый иранским руководством к судьбе единоверцев-шиитов в Персидском 
В.П. Кириченко. Шиитский фактор в отношениях арабских стран Персидского залива и Ирана

заливе, воспринимается руководством арабских стран как вмешательство во внутренние дела. Во-вторых, есть основания полагать, что само существование по соседству с ними современного Ирана, как государства с республиканской формой правления, установленной к тому же революционным путем - путем свержения «легитимного» монархического режима, расценивается элитами арабских монархий крайне негативно и влияет на их восприятие иранской внешней политики.

Подводя итог, следует отметить, что дискриминационная политика монархий Персидского залива в отношении проживающих в них шиитов не только чревата дестабилизацией внутриполитической ситуации в этих странах, но и вредит их отношениям с соседним Ираном. Данная политика не конструктивна: она не способствует консолидации общества; предубеждения против шиитов и их преследования со стороны властей Персидского залива, значительно осложняя положение шиитского меньшинства, по сути, подталкивают его к политической радикализации и открытому неповиновению. Неконструктивна она и потому, что, вызывая дипломатические демарши Ирана и антиарабские настроения в Иране, она вносит весомый вклад в воспроизводство в странах Персидского залива преувеличенных представлений об «иранской угрозе». В действительности эта угроза не идет ни в какое сравнение с той, которую представляет группировка ДАИШ.

\section{ПРИМЕЧАНИЯ}

1 По некоторым данным шииты составляют 10 \% проживающих в мире мусульман. Их численность насчитывает от 154 до 200 млн человек [22]. Шииты составляют большинство населения Ирана, Бахрейна, Ирака и Азербайджана, а также значительную часть населения Ливана и Йемена. Различные шиитские общины существуют практически во всех мусульманских странах.

2 Ашура- 10 мухаррама (то есть 10-е число первого месяца мусульманского года по Хиджре). Отмечается как траур по шиитскому имаму Хусейну в течение десяти первых дней мухаррама с кульминацией траурных церемоний в день ашуры. В этот день, 10 октября 680 г., в сражении при Кербеле были убиты имам Хусейн, его брат Аббас и 70 их сторонников. В память об их мучени- ческой смерти шииты совершают ежегодные траурные церемонии - тазийа [7, с. 33].

\section{СПИСОК ЛИТЕРАТУРЫ}

1. Алексеев, В. Страны ССАГПЗ против нормализации отношений с Ираном / В. Алексеев. Электрон. текстовые дан. - Режим доступа: http:// www.iran.ru/news/analitycs/96645/Strany SSAGPZ protiv_normalizacii_otnosheniy_s_Iranom (дата обращения: 30.12.2015). - Загл. с экрана.

2. Ближний Восток. Информационный центр. Электрон. текстовые дан. - Режим доступа: http:// www.middleeast.org.ua/about/oman 1.htm (дата обращения: 30.12.2015). - Загл. с экрана.

3. Ближний Восток: Что год грядущий нам готовит? - Электрон. текстовые дан. - Режим доступа: http:// ru.exrus.eu/Blizhny-Vostok-Chto-god-gryadushchy-namgotovit-id53176ebaae20158975 d2d694/ main (дата обращения: 30.12.2015). - Загл. с экрана.

4. Глава Ирана осудил нападение на посольство Саудовской Аравии в Тегеране. - Электрон. текстовые дан. - Режим доступа: http:/www.rg.ru/ 2016/01/03/rouhani-site-anons.html (дата обращения: 04.01.2016). - Загл. с экрана.

5. Долгов, Б. Не удержался / Б. Долгов // Эксперт. - 2012. - № 30-31. - С. 50-52.

6. Иран ставит военно-политические задачи // Взгляд. - Электрон. текстовые дан. - Режим доступа: http://vz.ru/politics/2013/2/8/619142.html (дата обращения: 30.12.2015). - Загл. с экрана.

7. Ислам: Энциклопедический словарь / под ред. С. М. Прозорова. - М. : Наука, 1991. -315 с.

8. Мелкумян, Е. С. Партия «Хизбалла» в Кувейте / Е. С. Мелкумян. - Электрон. текстовые дан. Режим доступа: http://www.iimes.ru/?p=6944 (дата обращения: 30.12.2015). - Загл. с экрана.

9. Петрушевский, И. П. Ислам в Иране в VIIXV вв. / И. П. Петрушевский. - Л. : Изд-во ЛГУ, 1966. $-398 \mathrm{c}$.

10. Роухани: Эр-Рияд не сможет скрыть «преступление» разрывом дипотношений. - Электрон. текстовые дан. - Режим доступа: http://ria.ru/world/ 20160105/1354888431.html (дата обращения: 05.01.2016). - Загл. с экрана.

11. Сажин, В. И. Иран: апрель 2011 г. Военно-политическая ситуация / В. И. Сажин. - Электрон. текстовые дан. - Режим доступа: http://www.iimes.ru/rus/ stat/2011/06-06-11c.htm (дата обращения: 30.12.2015). Загл. с экрана.

12. Самсонов, А. Оман за «особые» отношения с Ираном / А. Самсонов. - Электрон. текстовые дан. Режим доступа: http://topwar.ru/8578-oman-za-osobyeotnosheniya-s-iranom.html (дата обращения: 30.12.2015). -Загл. с экрана. 
13. Субх, М. А. О преследовании представителей оппозиции в некоторых странах ССАГПЗ / М. А. Субх. - Электрон. текстовые дан. - Режим доступа: http://www.iimes.ru/?p=15136 (дата обращения: 30.12.2015). - Загл. с экрана.

14. Barzegar, K. 2008 Iran and the Shiite crescent: myths and reality/K. Barzegar // Brown Journal of World Affairs. -2008. -Fall-Winter.-Vol. XV, iss. 1. -P. 87-99.

15. Bröning, M. 2008. Don't fear the Shiites. The idea of a Teheran-controlled "Shiite crescent" over the greater Middle East is at odds with reality / M. Bröning // Internationale Politik und Gesellschaft. - 2008. Bd. 3. - P. 60-75.

16. Commins, D. 2006. The Wahhabi Mission and Saudi Arabia / D. Commins. - L. ; N. Y., 2006. - 287 p.

17. Forces armées d'Iran // Defense \& Securite Internationale. Hors Serie. - 2015. - N 40 (fevr.-mars). P. 74-75.

18. International religious freedom report for 2013: Kuwait. - Electronic text data. - Mode of access: http://www.state.gov/j/drl/rls/irf/religiousfreedom/ index.htm?year $=2013 \&$ dlid $=222299$ \#wrapper (date of access: 30.12.2015). - Title from screen.

19. Nakash, Y. 2003. The Shi' is of Iraq/Y. Nakash.Princeton : Princeton University Press, 2003. - 340 p.

20. Saudi Arabia - Shia. - Electronic text data. Mode of access: http://www.globalsecurity.org/ military/world/gulf/sa-shia.htm (date of access: 30.12.2015). - Title from screen.

21. Saudi police arrest prominent Shi'ite muslim cleric. - Electronic text data. - Mode of access: http:/ /www.reuters.com/article/us-saudi-arrestidUSBRE 8670 GH20120708 (date of access: 05.01.2016). - Title from screen.

22. Sunnis and Shia: Islam's ancient schism. Electronic text data. - Mode of access: http://www.bbc. com/news/world-middle-east-16047709 (date of access: 07.06.2016). - Title from screen.

23. United Arab Emirates: religious practices (Worldmark Encyclopedia. 2nd ed., 2014). - Electronic text data. - Mode of access: http://www.academia.edu/ 9409555/United_Arab_Emirates_Religious_Practices Worldmark_Encyclopedia_2nd_edition_2014_(date of access: 30.12.2015). - Title from screen.

24. USCIRF 2014. Annual report on religious freedom: Bahrain. - Electronic text data. - Mode of access: http://www.bahrainrights.org/en/node/6849 (date of access: 30.12.2015). - Title from screen.

\section{REFERENCES}

1. Alekseev V. Strany SSAGPZ protiv normalizatsii otnosheniy s Iranom [GCC Countries Against the Normalization of Relations With Iran]. Available at: http://www.iran.ru/news/analytics/96645/Strany_
SSAGPZ_protiv_normalizacii_otnosheniy_s_Iranom. (accessed December 30, 2015).

2. Blizhniy Vostok. Informatsionnyy tsentr [The Middle East. Information Centre]. Available at: http:// www.middleeast.org.ua/about/oman1.htm. (accessed December 30, 2015).

3. Blizhniy Vostok: Chto god gryadushchiy nam gotovit? [Middle East: What Is Next Year Preparing for Us?]. Available at: http://ru.exrus.eu/ Blizhny-Vostok-Chto-god-gryadushchy-nam-gotovitid53176ebaae20158975d2d694/main. (accessed December 30, 2015).

4. Glava Irana osudil napadenie na posolstvo Saudovskoy Aravii v Tegerane [The Head of Iran Disapproved the Attack on the Saudi Embassy in Tehran]. Available at: http://www.rg.ru/2016/01/03/ rouhani-site-anons.html. (accessed January 4, 2016).

5. Dolgov B. Ne uderzhalsya [Couldn't Hold on Itself]. Ekspert, 2012, no. 30-31, pp. 50-52.

6. Iran stavit voenno-politicheskie zadachi [Iran Sets Military and Political Tasks]. Vzglyad. Available at: http://vz.ru/politics/2013/2/8/619142.html. (accessed December 30, 2015).

7. Prozorov S.M., ed. Islam: Entsiklopedicheskiy slovar [Islam: Encyclopedic Dictionary]. Moscow, Nauka Publ., 1991. 315 p.

8. Melkumyan E.S. Partiya "Khizballa" $v$ Kuveyte [Hizballah Party in Kuwait]. Available at: http:// www.iimes.ru/?p=6944. (accessed December 30, 2015).

9. Petrushevskiy I.P. Islam $v$ Irane $v V I I-X V v v$. [Islam in Iran in the 7th-15th Centuries]. Leningrad, Izd-vo LGU, 1966. 398 p.

10. Roukhani: Er-Riyad ne smozhet skryt "prestuplenie" razryvom dipotnosheniy [Roukhani: Riyadh Cannot Cover Its "Crime” by Severing Political Relations]. Available at: http://ria.ru/world/20160105/ 1354888431.html. (accessed January 5, 2016).

11. Sazhin V.I. Iran: aprel 2011 g. Voennopoliticheskaya situatsiya [Iran: April 2011. Military and Political Situation]. Available at: http://www. iimes.ru/rus/stat/2011/06-06-11c.htm. (accessed December 30, 2015).

12. Samsonov A. Oman za "osobye" otnosheniya s Iranom [Oman Is for "Special" Relations With Iran]. Available at: http://topwar.ru/8578-oman-za-osobyeotnosheniya-s-iranom.html. (accessed December 30, 2015).

13. Subkh M.A. O presledovanii predstaviteley oppozitsii $v$ nekotorykh stranakh SSAGPZ [On the Persecution of the Opposition Members in Some GCC Countries]. Available at: http://www.iimes.ru/?p=15136. (accessed December 30, 2015).

14. Barzegar K. 2008 Iran and the Shiite Crescent: Myths and Reality. Brown Journal of World Affairs, Fall-Winter, 2008, vol. XV, iss. 1, pp. 87-99.

15. Bröning M. 2008. Don't Fear the Shiites. The Idea of a Teheran-Controlled “ShiiteCrescent”' Over the Greater 
В.П. Кириченко. Шиитский фактор в отношениях арабских стран Персидского залива и Ирана

Middle East Is at Odds With Reality. Internationale Politik und Gesellschaft, 2008, iss. 3, pp. 60-75.

16. Commins D. 2006. The Wahhabi Mission and Saudi Arabia. London; New York, 2006. 287 p.

17. Forces Armées d'Iran. Defense \& Securite Internationale. Hors Serie, 2015, no. 40 (FebruaryMarch), pp. 74-75.

18. International Religious Freedom Report for 2013: Kuwait. Available at: http://www.state.gov/j/drl/ rls/irf/religiousfreedom/index.htm?year $=2013 \&$ dlid=222299\#wrapper. (accessed December 30, 2015).

19. Nakash Y. 2003. The Shi is of Iraq. Princeton, Princeton University Press, 2003. 340 p.

20. Saudi Arabia - Shia. Available at: http:// www.globalsecurity.org/military/world/gulf/sashia.htm. (accessed December 30, 2015).
21. Saudi Police Arrest Prominent Shi'ite Muslim Cleric. Available at: http://www.reuters.com/ article/us-saudi-arrest-idUSBRE8670GH20120708. (accessed January 5, 2016).

22. Sunnis and Shia: Islam's Ancient Schism. Available at: http://www.bbc.com/news/world-middleeast-16047709. (accessed June 7, 2016).

23. United Arab Emirates: Religious Practices (Worldmark Encyclopedia, 2nd edition 2014). Available at: http://www.academia.edu/9409555/ United_Arab_Emirates_Religious_Practices_Worldmark Encyclopedia_2nd_edition_2014. (accessed December 30, 2015).

24. USCIRF 2014 Annual Report on Religious Freedom: Bahrain. Available at: http://www. bahrainrights. org/en/node/6849. (accessed December 30, 2015).

\section{Information About the Author}

Vladimir P. Kirichenko, Candidate for a Degree, Institute of Oriental Studies, Russian Academy of Sciences, Rozhdestvenka St., 12, 107031 Moscow, Russian Federation, black-whit@yandex.ru.

\section{Информация об авторе}

Владимир Павлович Кириченко, соискатель Института востоковедения РАН, ул. Рождественка, 12, 107031 г. Москва, Российская Федерация, black-whit@yandex.ru. 